\title{
The rich get richer and the poor get poorer - the Matthew mechanism as an approach to explain selection effects and the occurrence of multiple medalists in the "production" of international success in alpine ski racing
}

\author{
Michael Barth ${ }^{1, *}$, Arne Güllich² \& Eike Emrich ${ }^{3}$ \\ 1 Department of Sport Science, University of Innsbruck, Austria \\ 2 Department of Sport Science, University of Kaiserslautern, Germany \\ 3 Department of Sport Science, Economics and Sociology of Sport, Saarland University, Saarbrücken, Germany \\ * Corresponding author: Department of Sport Science, University of Innsbruck, Fürstenweg 185, 6020 Innsbruck, Austria \\ Email: michael.barth@uibk.ac.at
}

\section{ORIGINAL ARTICLE}

\section{Article History:}

Submitted $10^{\text {th }}$ October 2017

Accepted $11^{\text {th }}$ June 2018

Published $31^{\text {st }}$ July 2018

Handling Editor:

Otmar Weiß,

University of Vienna, Austria

Editor-in-Chief:

Martin Kopp

University of Innsbruck, Austria

Reviewers:

Reviewer 1: Marcel Fahrner, University of Tübingen, Germany

Reviewer 2: Anonymous

\begin{abstract}
The study addresses two questions that are under debate in the literature and exemplifies their examination in alpine ski racing. Firstly, are successful athletes the product of a long-term continuous intervention and/or socialization process or do they rather emerge via repeated selection processes? Secondly, to which extent is a nations' collective success composed of many athletes' singular successes or of a few athletes' multiple successes?

The study involved the national squad of the Austrian Ski Federation. Data collection comprised membership in a national squad and World or Olympic medal success and was carried out via document analysis (seasons: 1986-2016).

The mean annual athlete turnover rate ranged from $24-57 \%$ across squad levels while the turnover rate varied substantially over time within each squad level. Among all national squad athletes, the incidence of being a successful (i.e., medal winning) National Team athlete was $8.9 \%$ (95\% Cl: 6.0\%; $12.5 \%)$. Twenty-eight athletes won a total of 112 medals, 21 athletes achieved winning two or more medals. The six most successful athletes won 56 medals, comprising $50 \%$ of all medals won.

The study suggests that successful elite athletes emerge from repeated selection and filtering processes. The observation of multiple medalists and a high concentration of exceptional success among a few athletes is reflected with regard to potential causes that rest on characteristics of the individual athlete, on social mechanisms (e.g., Matthew mechanism) of the elite sports system, or both.

Keywords:

Alpine ski racing - elite sport development - international sporting success - Matthew mechanism - survival function
\end{abstract}

Citation:

Barth, M., Güllich, A. \& Emrich E. (2018). The rich get richer and the poor get poorer - the Matthew mechanism as an approach to explain selection effects and the occurrence of multiple medalists in the "production" of international success in alpine ski racing. Current Issues in Sport Science, 3:008. doi: 10.15203/CISS_2018.008 


\section{Introduction}

In times of cold war the sporting success of a nation's athletes at major international sporting events was supposed to vicariously demonstrate the superior performance capacity of a nation and/or social system (for using sport as a means to stabilize an optimizing dictatorship in times of the cold war in the GDR see Pierdzioch, Emrich, \& Klein, 2014). Even today, international championships not only imply the competition among individual athletes but also among nations. Although nowadays there are repeated critical discussions on this topic and the downsides of this rat race come increasingly to notice (e.g., Humphreys, Johnson, Mason, \& Whitehead, 2016; for rat race see basically Akerlof, 1976), it seems that this second level competition between nations has lost none of its significance. Especially the medals table enables global contests to compete for "soft" prizes such as attention, legitimacy, and prestige (Haut, Prohl, \& Emrich, 2016; Werron, 2012; for the meaning of soft power of nations see e.g., Emrich, Gassmann, Haut, Pierdzioch, \& Prohl, 2015). As a result, producing sporting success is an important subject for many nations.

National sport associations and sport governing bodies around the world have established elite sport development programs aiming to increase the probability of a nation's athletes' success. Respective (governmental) investments have been increased massively over recent decades (e.g., de Bosscher, Bingham, Shibli, van Bottenburg, \& de Knop, 2008; Emrich, Pierdzioch, \& Rullang, 2013; Oakley \& Green, 2001). National collective sporting success in terms of the number of won medals is typically seen as the ultimate goal of these programs. Winning as many medals as possible is an important objective of governments, sport governing bodies and sport associations (Bundesministerium des Innern, Deutscher Olympischer Sportbund, \& Sportministerkonferenz, n.y.; Güllich \& Cobley, 2017; Wissenschaftliche Dienste des Deutschen Bundestages, 2012; regarding the low perceived importance of the medal table in the German population, Haut et al., 2016).

Although elite sport development programs may differ greatly across sports and countries, some critical core elements can be identified:

1. The difference between the individual and collective level: the goal of national success in the medals table lies on the collective level in terms of the aggregation of a nation's athletic achievements across individual athletes and different sports, compared to other nations. However, this goal is primarily pursued by applying training and athlete service measures (e.g., high-profile coaching, physiotherapy, performance analysis, sport-medical care, nutritional and career counselling) at the individual level to facilitate an athlete's performance progress.

2. The difference between performance and success: the goal is at the level of success (i.e., performance differences between athletes or teams in a defined competition and their social valuation) while the goal can only be pursued by attempting to facilitate athletes' performance. The opponents' performance, however, cannot be influenced and therefore, success can only partly be controlled at best. Furthermore, medal success is a zero-sum game in which each participant's gain or loss is exactly balanced by the losses or gains of the other parties involved (e.g., Emrich \& Pierdzioch, 2012).

3. The "production" of success: the approaches draw on the assumption that the production of sporting success follows the principle of the manufacture of goods depicted in the production function, in that success can be controlled by applying defined measures to the individual athlete, in short by varying the input and modifying the throughput. Namely, most athlete-related promotion measures aim at increasing the input in terms of enlarging the athlete's available time for practice and competition (extensive timeeconomy) and to use that time efficiently (intensive timeeconomy; see Barth, 2015; Güllich \& Cobley, 2017; Güllich \& Emrich, 2012).

Bringing these critical key elements together, an interesting chain of causal assumptions emerges with respect to the fundamental ideas of elite sport development programs: (1) Talent identification programs identify the most promising young athletes. (2) These athletes are integrated in long-term continuous development programs. (3) The successive enhancement of the individual athletes' performance increases their probability of becoming a successful athlete at international sports competitions. (4) The different athletes' increased performances aggregate and lead to improved collective success. According to this individualistic approach, a nation's elite athletes will have developed exactly from the ranks of the selected athletes involved in the program for extended periods (Güllich \& Emrich, 2012).

Although this seems to be the fundamental idea of the "production" of sporting success there exists a second, complementary but different, (collectivistic) approach for sport associations and sport governing bodies how they can essentially pursue national collective success (Emrich \& Güllich, 2005; Güllich \& Cobley, 2017; Güllich \& Emrich, 2012). In the course of repeated selection procedures through the different age categories and program stages, selections are sometimes revised. Also, deselected athletes may be replaced by "newcomers" who have developed more prosperously outside the elite sport development programs. Such a collectivistic approach to athlete support programs is characterized by high "permeability" of the program and turnover of athletes through all stages, and so a specific relationship between athlete stock and athlete flow within the program develops. According to this approach, it is of subordinate relevance who exactly become the internationally successful performers and the collective of outstanding performers emerges gradually in the course of repeated selection and deselection procedures (i.e., a selection effect). 
The resulting question, whether successful athletes are the product of a long-term continuous intervention and/or socialization process (individualistic approach) or they rather emerge via repeated selection processes (collectivistic approach) was recently addressed by several authors. Güllich, Anthes, and Emrich (2005), Güllich and Emrich (2012, 2013), Güllich (2014a), and Güllich and Cobley (2017) investigated the question for elite sport development programs in general and Emrich, Fröhlich, Klein, and Pitsch (2009) as well as Flatau and Emrich (2013) especially for elite sport schools. These studies consistently demonstrated that the population of successful top athletes emerged from repeated selection and de-selection processes within and across the various age ranges and stages, rather than resulting from their early selection and long-term continuous nurture applied to them.

These studies were all (except Güllich's, 2014a, study in German soccer) based on the combined analysis of multiple sports, implying potential confounding interactions among the sport, success probability, intervention/socialization and selection effects. In the present study, we purpose to investigate the question within a single, individual sport. We considered Austrian alpine ski racing an appropriate and also particularly interesting case to exemplify this investigation for five reasons: (1) It is an individual sport providing the determination of individual success differences. (2) It is a multi-disciplinary sport where an individual athlete can be successful in one or various disciplines (Downhill, Super-G, Giant Slalom, Slalom, and Alpine combined). (3) It is a very popular sport within Austria (and many other countries) and elite alpine skiing is highly commercialized and professionalized domestically and internationally, implying great international strength of competition, while Austria is one of the world leading nations. Furthermore, (4) a combination of voluminous training together with specific equipment and facilities (i.e., skis, race suit, mountains, snow, and slopes) is required to reach the top level, suggesting that the production process likely follows the individualistic approach, compared to other sports (e.g., soccer). Besides, (5) the relevant data are available through three successive decades (see below: Methods).

The first aim of this study was thus to analyze whether successful alpine ski racers are the product of a long-term continuous intervention and/or socialization process or whether they rather emerge via the course of repeated selection processes.

Looking more closely at this aim and reflecting it relative to the ultimate goal of governmental sports funding, another problem emerges that is empirically unstudied to date. Whether an athlete is characterized as successful or not is commonly defined by determining whether an athlete has or has not reached a defined success level during his/her career. Numerous studies distinguished more and less successful athletes in order to compare their participation histories (e.g., Carlson, 1988; Emrich \& Güllich, 2005; Güllich, 2014b, 2017, 2018; Güllich \& Emrich, 2014; Hornig, Aust, \& Güllich, 2016; Johnson, Tenenbaum, \& Edmonds, 2006; Moesch, Elbe, Hauge, \& Wikman, 2011; Moesch, Hauge, Wikman, \& Elbe, 2013; van Rossum,
2000) or psychosocial biographies (e.g., Collins, MacNamara, \& McCarthy, 2016; Hardy et al., 2017). ${ }^{1}$ Furthermore, their involvement in elite sport development programs was investigated (Barth, Emrich, \& Daumann, 2017; Emrich, 1996; Emrich et al., 2009; Emrich \& Güllich, 2005; Güllich, 2014a; Güllich \& Cobley, 2017; Güllich \& Emrich, 2012).

However, these studies distinguished athletes based on a single measurement of their current success level or the highest success ever achieved in the course of their career. More precisely, to be labeled as "successful" an athlete had to be successful at the defined level only once. Individual variation of the frequency of attaining that success level has not been considered in quantitative empirical investigations. Athletes achieving the defined success level once or various times were treated as the same success level. That is, the traditional approach seems insufficient with a view to the ultimate goal of elite sport development programs defined above - winning as many medals as possible on the collective level. It would be especially interesting for a national sports system if individual athletes were not only successful once, but several times, implying that investments made in the development of one athlete would pay off by multiplied return in terms of success. Singular examples of multiple medalists are well known - Marit Björgen, Usain Bolt, Mo Farah, Allyson Felix, Chris Hoy, Hermann Maier, Michael Phelps, Steven Redgrave, or for instance in earlier days: Nadia Comaneci, Jesse Owens, or Mark Spitz. Are these athletes and their multiple successes exceptional individual outliers or rather a systematic phenomenon that can be empirically evidenced to occur with considerable frequency? This implies the question to what extent national collective medal count is rather composed of many athletes achieving a singular medal or relatively few athletes achieving multiple medals.

To the best of our knowledge, no designated study quantitatively differentiated singular versus multiple success of athletes at major international championships such as Olympic Games or World Championships. ${ }^{2}$ Thus, we should first of all clarify, if the multiple medalist is a systematic phenomenon and if we should further differentiate frequencies of individual achievements.

Therefore, the second aim of this study was to investigate to what extent a nation's collective international success in alpine ski racing consists of many athletes being successful once (low concentration of success) or only few athletes being successful several times (high concentration of success).

1 Besides, some studies examined athletes' multi-year differential stability of competitive performance across numerous sports (e.g., Bonetti \& Hopkins, 2010; Bullock, Hopkins, Martin, \& Marino, 2009; Hopkins, 2005; Malcata \& Hopkins, 2014; McGuigan \& Kane, 2004; Nibali, Hopkins, \& Drinkwater, 2011; Paton \& Hopkins, 2005, 2006; Smith \& Hopkins, 2011; Spencer, Losnegard, Hallén, \& Hopkins, 2014). But they did not record international success.

2 The studies of Güllich (2014a) and Hardy et al. (2017) involved multiple gold medalists but their focus were athletes' participation histories and psychological characteristics. In addition, the comparison groups were "only" national class peers, respectively. 


\section{Methods}

Sample

The study takes the form of an initial case study, involving the national squad of the Austrian Ski Federation. An advantage of this case is that continuous squad lists were available over more than 30 successive seasons, which is rarely provided in other federations. Above that, the Austrian Ski Federation has a long history of a relatively stable structuring of squads. Data collection was carried out via document analysis using two sources. Firstly, the annual squad data of the federation from the seasons 1986 until 2016 (31 seasons), and secondly the International Ski Federation database. The first source served to list the national squad athletes (total $n=554$ ), including the two variables "season" and "squad level" (National Team, A-Squad, BSquad, Junior Squad). The international database was used to identify the medalists at Olympic and World Championships. ${ }^{3}$

\section{Data Analysis}

For descriptive statistics, frequency distribution, mean value, and, in case of skewed data distribution, median (Mdn) and interquartile range (lqr) were used. The annual turnover of squad members within each squad level was calculated according to Güllich and Emrich (2012) as: ${ }^{4}$

(Number of new athletes assigned to the squad + number of athletes who have left the squad) $/ 2$ Average size of the squad of the two seasons of the transition

To examine the season-to-season variability of the annual athlete turnover, Pearson's Coefficient of Variation was employed $\left(=\frac{s_{x}}{\bar{x}} * 100 \%\right)$.

The form of data entry also enabled the analysis of life expectancy/career duration drawing on the mortality tables, whereas the respective random sample test is limited to those athletes whose squad career can be mapped completely. The criterion for the beginning of a squad career was set as no registration in a squad file for at least the two recent seasons. The end of a squad career was defined by two or more successive seasons without an athlete's registration in a squad file or by a public announcement of an athlete's retirement. This reduced the random sample from $n=554$ to $n=351$.

In order to consider possible gender-specific differences in the survival function within the National Team (limited to athletes who attained this level), the survival function was depicted according to Kaplan-Meier. The meaningful application of the

3 We considered medals at these major world-level championships because they reflect the goal variable of national sport organizations (see above: Introduction).

4 It should be noted that these authors defined the age-related expected and empirical athlete flow separately. Only the observed flow is analyzed here. Unlike football and other sports, specific age limits of different national squad stages do not exist in (Austrian) alpine ski racing. This means that age does not automatically result in a certain newcomer quota.
Log-Rank Test for the whole period was not possible due to the violation of the assumption of the proportionality of the hazards (Bewick, Cheek, \& Ball, 2004; Zwiener, Blettner, \& Hommel, 2011). Therefore, the random sample was limited so that the difference in the interval between the two intersection points could be calculated (Held, 2010). Furthermore, and due to the violation of singular pre-conditions for parametric procedures (Bortz \& Schuster, 2010), the following nonparametric inferential statistical methods were used: Mann-Whitney UTest, Kruskal-Wallis H-Test, and Spearman's rank correlation coefficient. Besides, the $95 \%$ confidence interval $(95 \% \mathrm{Cl})$ will be presented in case of the calculation of the incidence of being a successful athlete among all national squad athletes.

To examine the distribution of the individual number of medals among the podium winners for males and females (concentration), the Lorenz Curve and the normalized Gini Coefficient (Lorenz-Münzner Coefficient) [0;1] were used. The further the Lorenz-Münzner Coefficient tends towards "1", the stronger is the concentration of success among fewer athletes.

Finally, we distinguished between "serial" and "multiple" medalists, where "serial" medalists won their medals at various different (not necessarily successive) events in only one single discipline. "Multiple" medalists comprise athletes winning their medals in at least two different disciplines. ${ }^{5}$

Evaluation was carried out using IBM SPSS Statistics 24.

\section{Results}

This section is structured in accordance to our two research questions. First, we report the results concerning the athletes' movements across the different squad levels, the turnover rates as well as a comparison of female and male National Team members' survival function. The second part deals with results on the question if a nation's collective success is highly concentrated on a small number of athletes.

\section{Career paths of athletes}

Figure 1 highlights the male and female mean annual athlete movements across the four squad levels of the Austrian Ski Federation over 31 seasons.

The comparison of the squad structures for women and men reveals that the respective Junior Squads were similar in size. However, more men than women were nominated for the $\mathrm{Na}$ tional Team, A-, and B-Squad, respectively. Each of by-passing a squad level, a direct "side-entry" at a higher level and demotion from a higher to a lower squad level occurred but were very infrequent. Figure 1 also shows that the proportion of persisting athletes seems to increase in the National Team compared to the other squad levels.

5 This includes that a multiple medalist may also have won several medals in one discipline. 


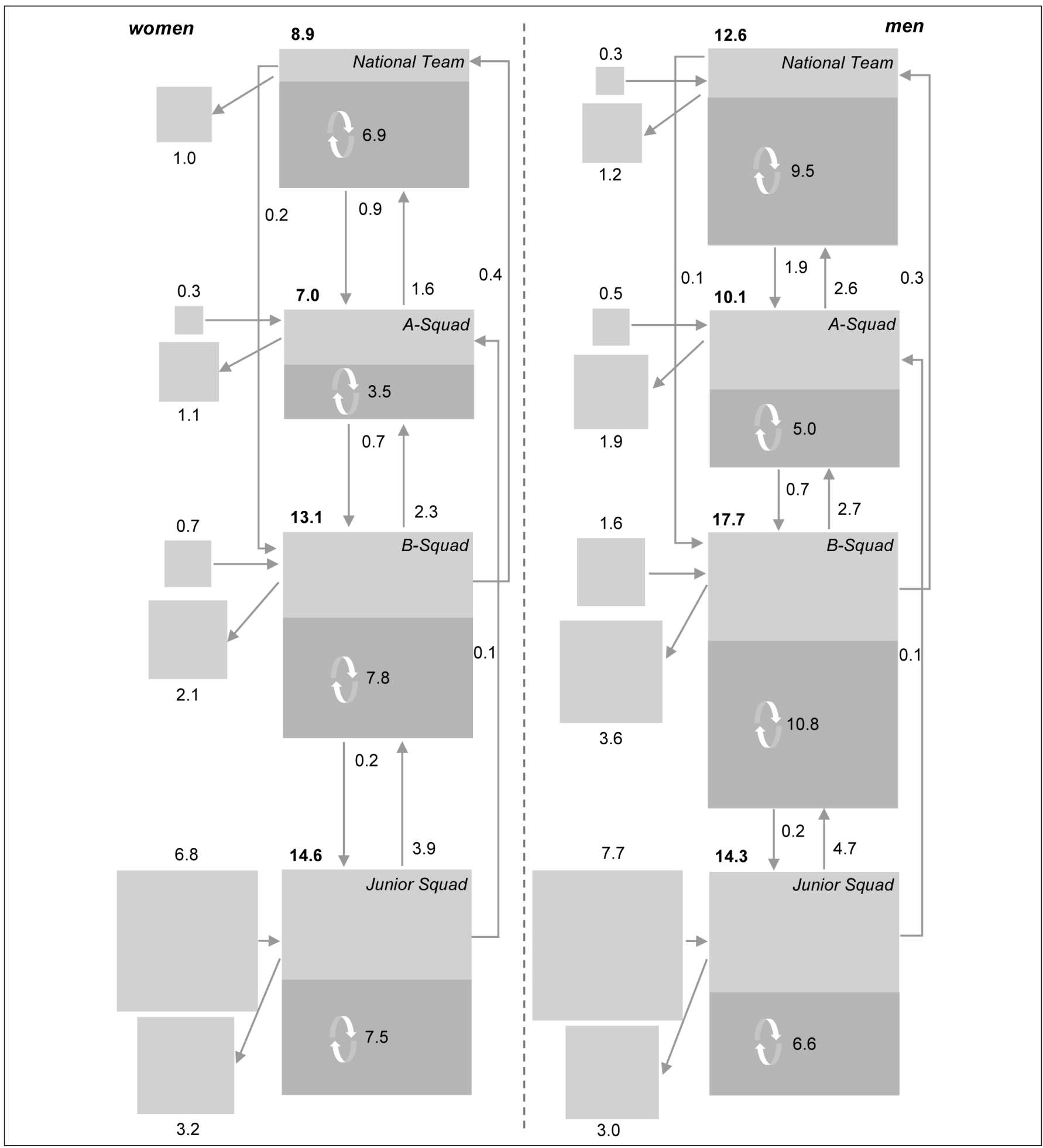

Sample depiction: the women's Junior Squad comprises 14.6 athletes on average across all seasons. Average season-to-season transitions are as follows: 7.2 athletes leave the Junior Squad, of whom 3.9 athletes progress to the B-Squad, 0.1 athletes progress directly to the A-Squad and 3.2 have no squad status in the new season. 7.1 athletes enter the Junior Squad - to which 6.8 had no squad status in the previous season and 0.2 athletes descend from the B-Squad (difference due to rounding). The difference between newcomers and leavers results from the fact that the number of athletes in the women's Junior Squad slightly decreased during the period studied (from 17 athletes in the season 1986 to 14 athletes in the season 2016). In this context, the expansion of the B-Squad has to be noted (women from 7 to 19 and men from 14 to 22 athletes during the period studied). The average number of newcomers and leavers vary accordingly. Note: values $<.05$ are omitted.

Figure 1: Average athlete movements (season-to-season transitions) among the women's and men's squad levels in the Austrian Ski Federation 


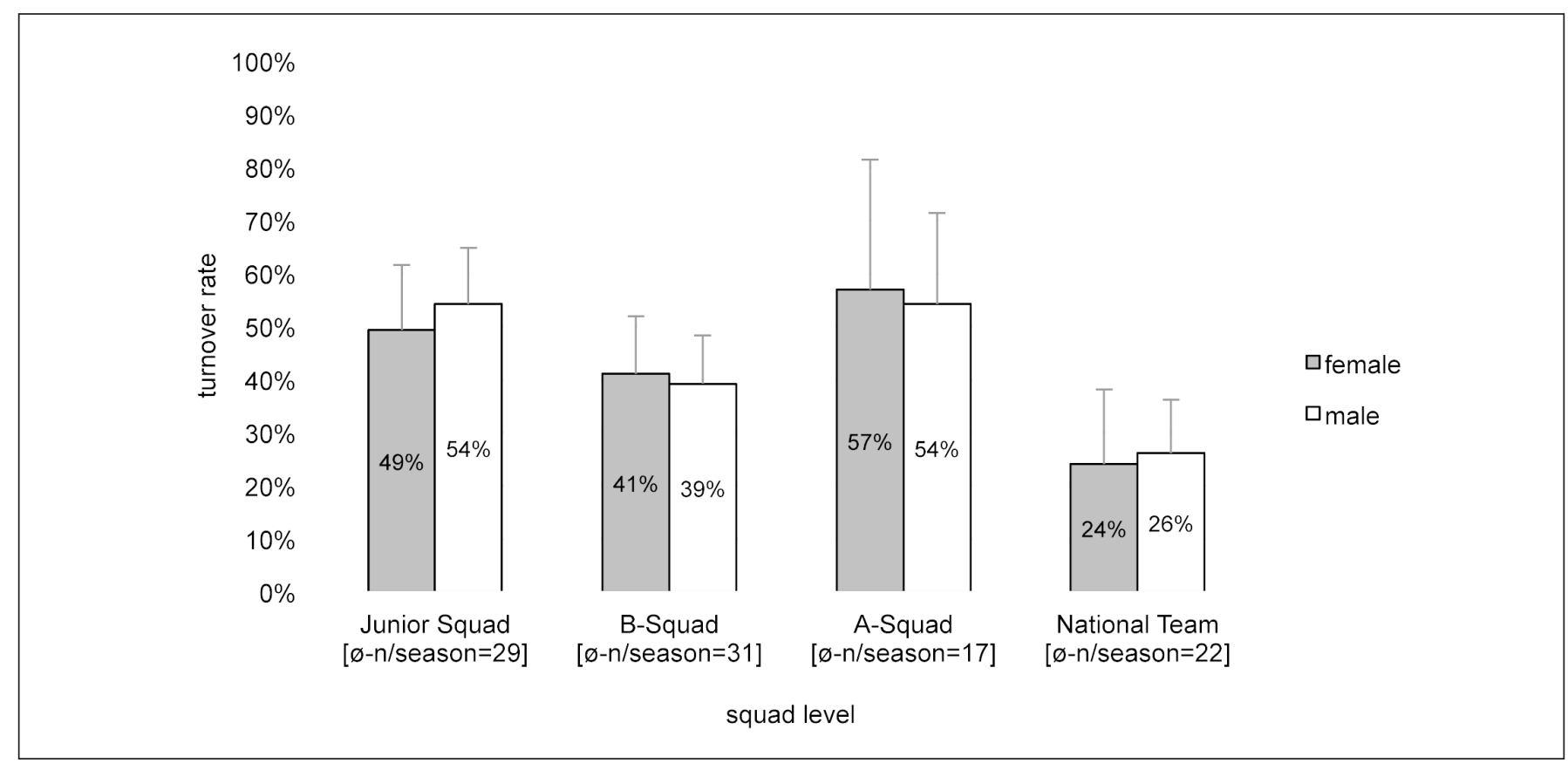

Note: The values represent the average values of the annual turnover rate. Due to the variation of the squad sizes over time, there are deviations from the values calculated in Figure 1. The error bars represent standard deviations.

Figure 2: Mean annual turnover rate within the 4 squad levels over 31 seasons

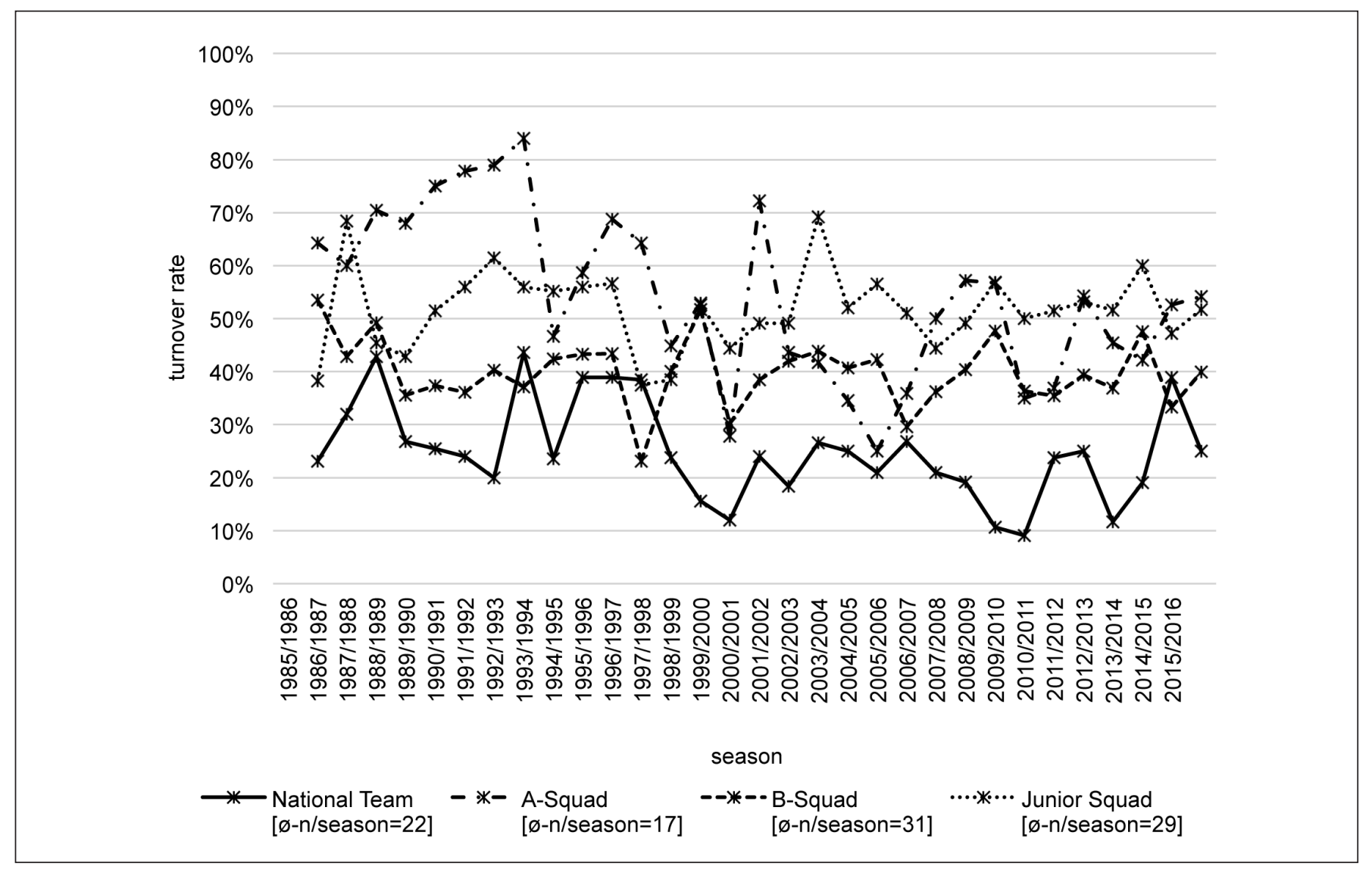

Figure 3: Season-specific turnover rate in the 4 levels of the national squad 


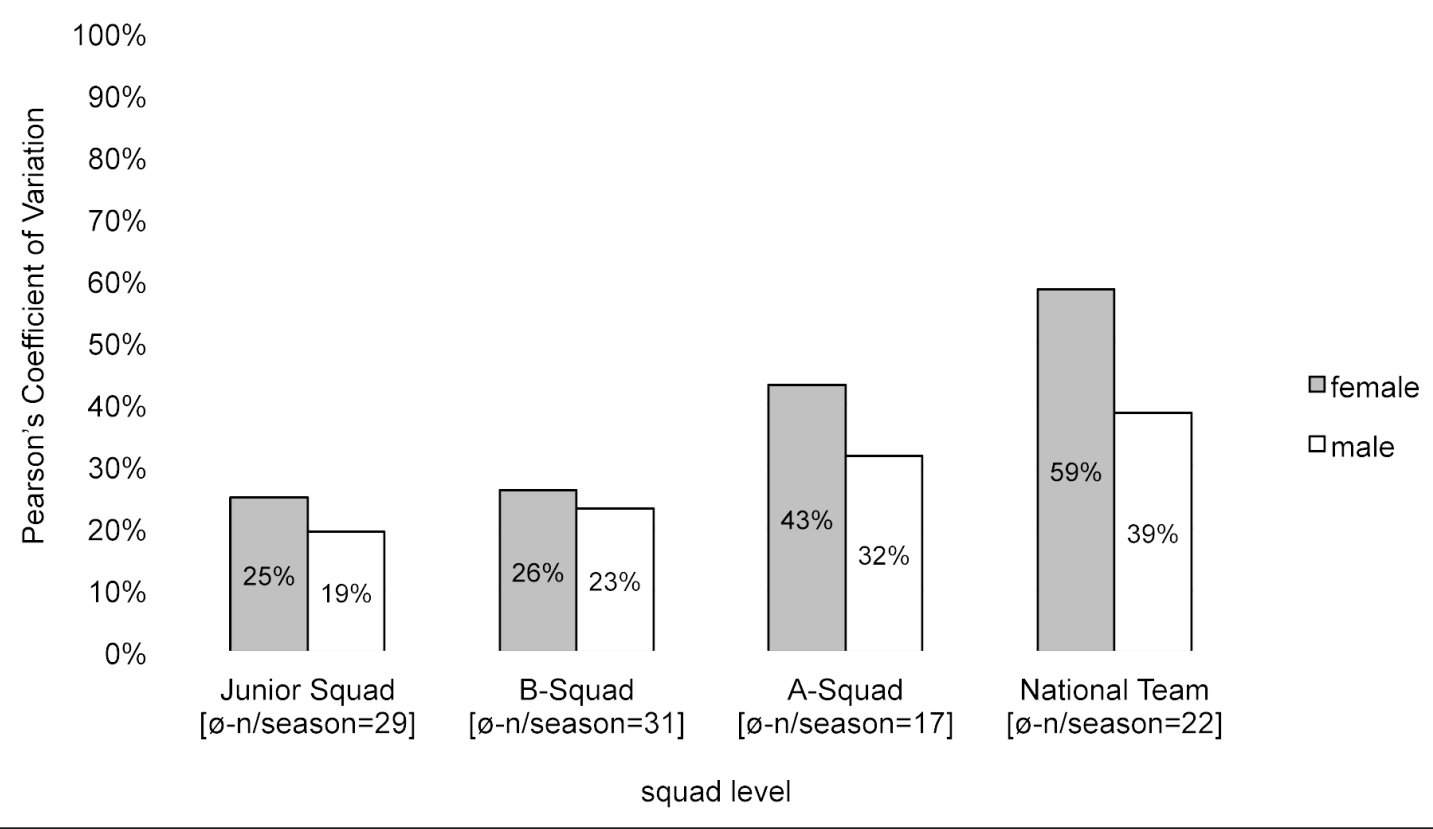

Figure 4: Pearson's Coefficient of Variation of the turnover rates through 31 seasons at the 4 squad levels

The mean annual turnover rates over 31 seasons within the four squad levels are illustrated for males and females in Figure 2. Comparison of the athlete turnover across the successive seasons reveals large season-to-season variation in the turnover rate (see Figure 3). At all squad levels, there was a noticeable change over time. The annual turnover rate ranged from $9 \%$ to $44 \%$ within the National Team, $25 \%$ to $84 \%$ within the A-Squad, $23 \%$ to $53 \%$ within the B-Squad and $38 \%$ to $69 \%$ within the Junior Squad. To analyze the variability of the turnover rate, the standard variations were standardized relative to their respective average value (Figure 4; cf. Methods).

It can be deduced from figures 2 and 4 that both National Teams exhibited the lowest average turnover rate over all seasons, but the largest relative season-to-season variation of the turnover rate, whereas the women's National Team shows greater variability than the men's National Team.

In a first interim summary, there are marked fluctuations in the turnover rate across the individual seasons. It is interesting that throughout the seasons, the National Teams show the lowest average seasonal turnover rates, but higher inter-seasonal variability of the turnover compared to the other squad levels.

Of the 351 national squad athletes in the Austrian Ski Federation whose squad career could be mapped completely, 57 (16.2\%) made it into the National Team. At the end of the $3^{\text {rd }}$ season, this proportion was $10.5 \%$, two seasons later it was $8.8 \%$ and after ten seasons $2.3 \%$.

On average, female National Team members remained at this highest squad level for 4 (lqr: 7) years and male members for 8 years (lqr: 6). Figure 5 displays the survival probability of male and female National Team members depending on the dura- tion of their membership. The analysis revealed a significant result $\left(\mathrm{X}^{2}(1, \mathrm{n}=36)=7.61, p=.006\right)$.

\section{Concentration of success}

Of the 57 athletes who were ever assigned to the National Team, 28 won at least one medal at international sporting events, 28 did not achieve this and for one person no information was available. For the group of athletes never reaching $\mathrm{Na}$ tional Team level no respective information was available for $12.6 \%(n=37)$. Among all other athletes, nobody won a medal. Among the 313 athletes with available data, the incidence of being a successful (medal winning) athlete among all national squad athletes was $8.9 \%$ (95\% Cl: $6.0 \% ; 12.5 \%){ }^{6}$ The total number of athlete-years in a squad for all athletes $(n=313)$ was 1,887 athlete-squad-years. The 28 medalists won a total of 112 medals in 85 athlete-squad-years, which means a $4.5 \%$ incidence rate of a successful athlete squad year. This signifies that for a successful athlete squad year, about 22 athlete-seasons were required, where 1.3 medals were won per successful year. In order to depict the concentration of success, the Lorenz Curve was employed (Figure 6).

Figure 6 demonstrates that $75 \%$ of the athletes won less than $50 \%$ of the medals. More precisely, the three most successful female athletes won a total of 27 medals and the three most successful male athletes 29 medals, making a total of 56 med-

6 This process can be seen as conservative. If the proportion calculation for athletes who were successful at least once is related to the total number of national squad athletes, this leads to a proportion of $8.0 \%$. 


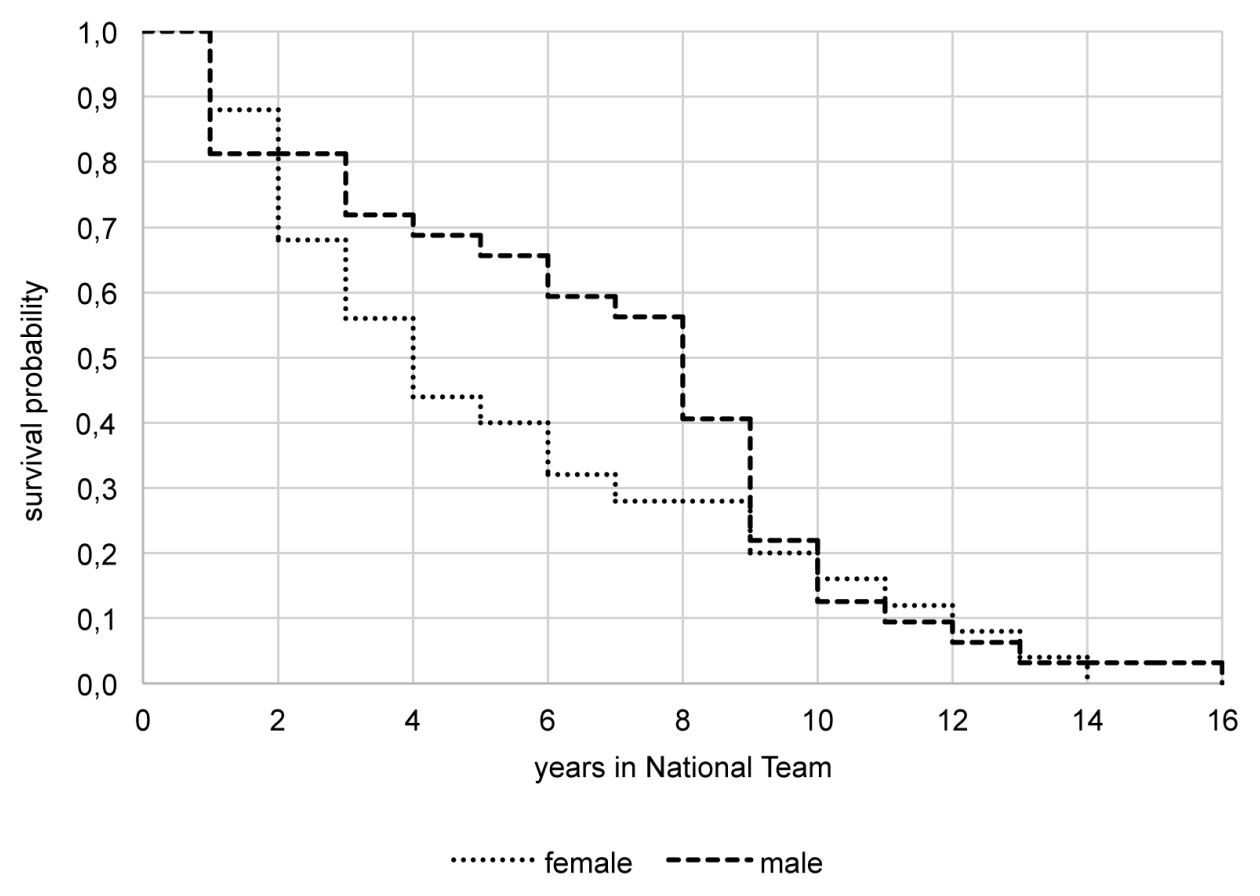

Figure 5: Survival functions of female and male National Team members $(n=57)$

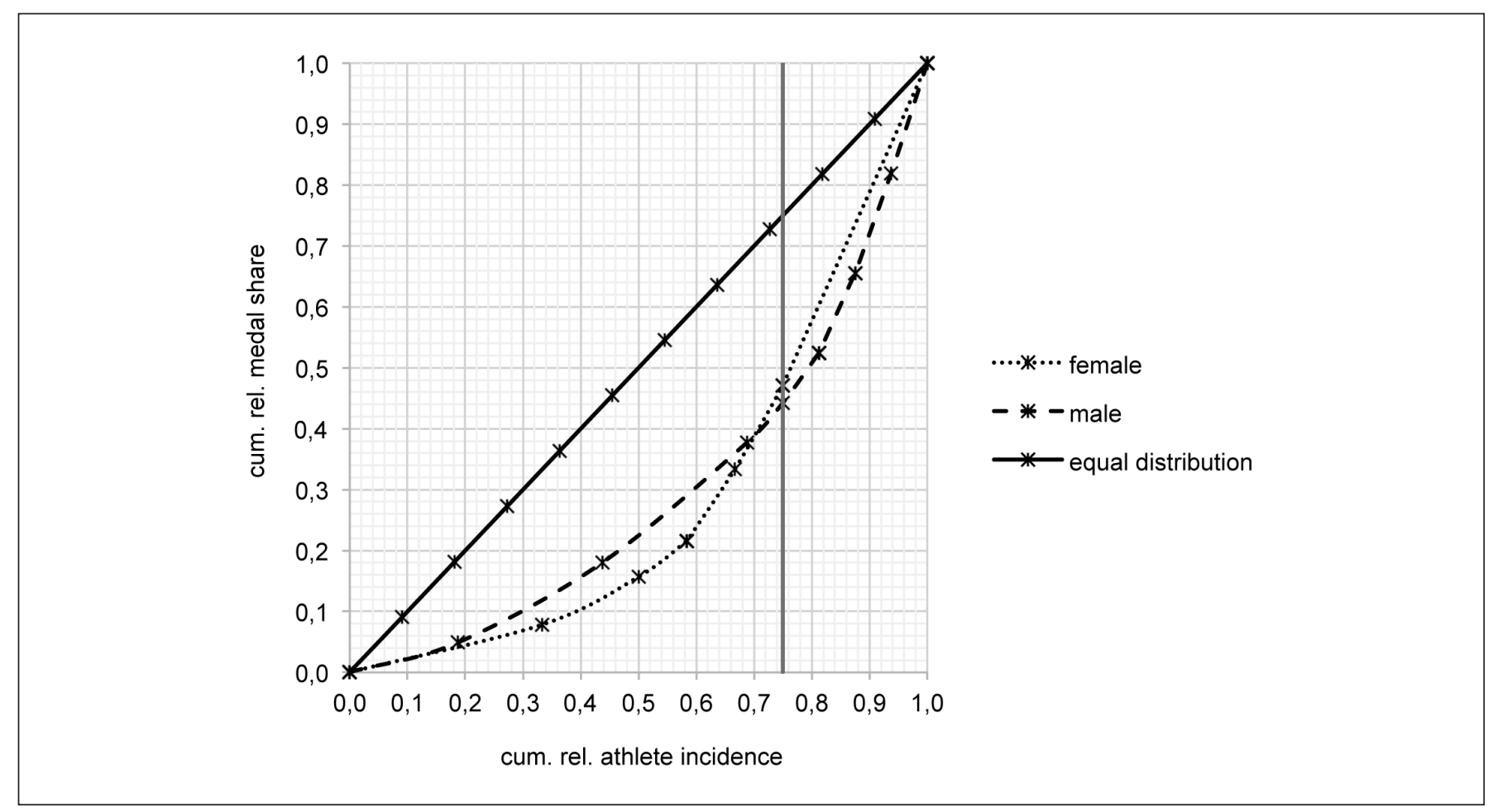

Figure 6: Lorenz Curve of the medal concentration for successful (medal winning) male and female athletes ( $\mathrm{n}=28$ ) 
als, comprising $50 \%$ of all medals won. For the female athletes group, the Lorenz-Münzner Coefficient is 0.46 , for the male athletes 0.43 .

Examining the athletes winning medals in more detail reveals that seven athletes won only one medal. Twenty-one athletes achieved winning two or more medals, where four athletes won their medals in one single discipline at various different championships (serial medalist). The 17 multiple medalists (athletes winning medals in at least two different disciplines) won 97 medals, equaling a proportion of $87 \%$ of all medals. Furthermore, 11 athletes won various medals at a single championship.

The analysis of the "length of persistence" in the squad system" among non-medalists, medalists winning one medal, and athletes winning various medals (multiple and serial medalists) revealed a significant difference $\left(x^{2}(2, n=313)=67.09, p=.001\right)$. The duration of the membership for non-medalists lasted 4 years on average, for athletes winning one medal 13 years and for athletes winning more than one medal 16 years. A low to moderate positive correlation between the duration of membership and the number of won medals was found $\left(r_{s}(313)=.46, p=.001\right)$. Overall, we could show that only a small proportion of national squad athletes achieved the status of a National Team member. Among these, there was a marked concentration of sporting success among a small number of athletes. Furthermore, the results show that the more successful athletes were the longer was the duration of their membership in the squad system of the Austrian Ski Federation. The comparison of the survival functions for the women's and men's National Team indicates a difference in their development.

\section{Discussion and Outlook}

This study analyzed season-to-season transitions across the different national squad levels of the Austrian Ski Federation. It extends earlier research not only in terms of a longer observation period of 31 successive seasons, but also - more importantly - by analyzing the season-to-season variation of the athlete turnover within each squad level and calculating survival functions for male and female athletes. Furthermore, the question whether multiple medalists are a systematic phenomenon was addressed and the amount of concentration of international success in alpine ski racing was calculated for the first time. The central findings concerning the first aim of this study were that all squad levels were characterized by considerable annual turnover of athletes, where the turnover rate exhibited large season-to-season variation. In the National Team, the annual turnover rate was lower but its season-to-season variation was larger than at lower squad levels - more so in females. Only $16.2 \%$ of national squad athletes ever made it into the National Team. In this context it should be kept in mind that the national

7 Years of membership within the four different squad levels in total. squad as such consists of Austria's best ski racers, which means that these athletes were a highly selective collective even at the lowest level of the national squad (Junior Squad).

The turnover rates within the Junior Squad, B-Squad, and ASquad were roughly in the range of those reported from German junior squads in various sports (Emrich \& Güllich, 2005; Güllich, 2014a; Güllich \& Emrich, 2012; Güllich, Papathanassiou, Pitsch, \& Emrich, 2001). Special attention should be paid to the results of the season-to-season variations in the seasonal turnover, as expressed by Pearson's Coefficient of Variation. These suggest that elite sport development apparently depends greatly on the variation of currently available athletes - which is clearly at odds with the notion of a stable production process in the sense of the production of goods. l.e., each of the athletes "stock" to work with sustainably, the athlete "flow" into and within the elite sport development system as well as the effectiveness of athlete service measures applied to the athlete are fraught with considerable uncertainty (Emrich \& Güllich, 2016; Güllich \& Emrich, 2012; Pierdzioch et al., 2014). Furthermore, the calculation of survival probabilities in the National Teams indicates a gender-specific difference between the second and ninth year of team membership, where the survival probability of male athletes tends to be higher than that of female athletes during this period.

Considered together, the findings concerning the first aim of this study are consistent with the suggestion from earlier studies (Emrich, 2010; Emrich \& Güllich, 2005; Emrich et al., 2009; Güllich \& Cobley, 2017; Güllich \& Emrich, 2012) that the population of successful elite athletes emerges from repeated procedures of selection, de-selection and replacement of athletes through the successive squad levels, rather than originating from talent identification at a young age and long-term continuous nurture within the squad system. By-passing a squad level or "side-entering" the squad system at high levels is possible and did occur but was - in (partial) contrast to the results of the above mentioned studies ${ }^{8}$ - very infrequent.

The incidence rate of a successful (medaling) athlete (-squadyears) within the national squad was low $(8.9 \%$ of the athletes and $4.5 \%$ of total athlete-squad-years). Above that, there was a marked inequality in the distribution of winning medals in terms of a pronounced concentration of many medals in a few athletes: For example, 6 out of 28 medalists won $50 \%$ of the total medals.

An athlete's number of won medals correlated modestly with the length of persistence in the squad system. In view of the seasonal athlete turnover and its inter-seasonal variation together with the Austrian Ski Federation's (n.y.a; n.y.b) successbased criteria for squad selection, it is plausible to assume that persistent medaling likely led to persistent squad membership rather than vice versa.

Interestingly, the majority of athletes (81\%) winning more than

8 It should be considered that unlike some other studies the population of the present study involved national squad athletes from junior level upward only. 
one medal were multiple but not serial medalists, meaning that they won their medals in at least two different disciplines. This group of medalists won 97 of the total 112 medals. The finding suggests that most athletes winning various medals were characterized by possessing highly adaptable skills and/or a broad repertoire of different skills enabling high performance in related, but different tasks. However, we must be careful with the generalizability of results concerning the concentration of success. The lower strength of competition in alpine ski racing (fewer nations) and the multiple similar disciplines may favor the occurrence of multiple medal winners compared to other sports such as basketball, football, rowing, tennis, triathlon, wrestling, etc.

\section{Theoretical considerations}

At this juncture, the interpretation of the findings with regard to causality has to be left open - it is conceivable that these may theoretically rest on characteristics of the individual athlete, on social mechanisms of the elite sports system, or both. We have the perception that the wide omission of discussion of possible causes for found results in the context of elite sport development programs reinforces implicit interpretations fortifying rationalized myths (for rationalized myths in organizations see basically Meyer \& Rowan, 1977). We therefore purposefully decided to now explicitly discuss conceivable causes and introduce a new approach at an explanation - the so-called "Matthew mechanism"s (Merton, 1968).

The observed infrequency of by-passing squad levels and of "side-entries" as well as the accumulation of multiple successes among a few athletes, may, on the one hand, point to the frequently suggested notion of the "talent of the century". On the other hand, however, it seems reasonable as well to suggest that the findings indicate the usage of effective interventions within the development programs. Finally, they may also be interpreted to show a partial temporal social closure based on the characteristics of the sports' competition rules itself, via obligatory "passage points" and/or the Matthew mechanism or a combination of these causes. However, a complete closure would rather preclude the observed influx rates, which were considerable even at the highest squad levels, and especially the year-to-year fluctuation of the influx rates.

An athlete's individual characteristics might for example concern an extraordinary "once in a century talent", a diverse range of athletic expertise enabling excellence in a range of disciplines, durability (remaining free from serious injury) in terms of the length of the international career, the skill of having the so-called "decisive punch" in the critical competitive situation or specific motivational profiles (Gould, Dieffenbach, \& Moffett, 2002; Hardy et al., 2017).

At the collective level of different sports, the probability of success and of multiple successes in particular is increased in sports where (a) an athletic ability or skill can be utilized in various dis-

9 We take this term from Bask and Bask (2015). ciplines (e.g., alpine ski racing, swimming), (b) participation in several disciplines within one championship is admissible (e.g., alpine ski racing, swimming), and (c) the international strength of competition is comparatively low (due to limited worldwide participation; e.g., alpine ski racing, biathlon, luge, or track cycling versus basketball, soccer, or athletics track events).

Contemporary organizational influence on development paths (cf. Barth, 2015; Emrich \& Güllich, 2005, 2016; Güllich \& Cobley, 2017) implies that obligatory "passage points" may emerge. For example, participation in a major international championship depends on the nomination by the (monopolistically acting) national sport governing body.

Also, temporarily less successful performers may be excluded from elite sport development programs so that they are not only disadvantaged at that time, but their chances of future success may be further diminished. These effects may occur at all levels and stages of the development system. That is, the organizational make-up may imply the emergence of social closure spirals. By contrast, success typically leads to extended subsequent support at the individual athlete level as well as at the level of sport associations. Considered together, it would seem very likely that a situation of cumulative advantages could arise, in that past sporting successes generate expectations of future success and thus greater resource supply, in this way creating the above mentioned Matthew mechanism.

This mechanism was coined in the scientific literature by Merton (1968) in his reference to the scientific reward system, and is used in a variety of domains (Rigney, 2010). However, it has drawn little attention within the realm of elite sports research. If we follow the suggested concept of a Matthew mechanism, this would mean that the cause of the incidence of a concentration is not (exclusively) to be found in the individual, but also (or rather) derived from the system. Consequently the introduction of market economy incentives should not be - as usually seems to be the case - intuitively associated with positive consequences, since these could also lead to manifold positive self-reinforcement (Matthew mechanism), possibly - and against their intended function - damaging the system.

When we introduce the concept of the possible existence of a Matthew mechanism in elite sport development we have to look more closely at the political processes in the recurring efforts to introduce reform, because the advantaged would dearly like to believe that they deserve their advantage (Rigney, 2010). This leads to the danger that not only the products of the Matthew mechanism, but also the processes themselves are protected by the advantaged via highly rationalized myths, because, in turn, it is precisely these advantages that put them in the social position to protect these advantages (Rigney, 2010; on ensuring legitimation by means of highly rationalized myths, as fundamental source see Meyer \& Rowan, 1977). Put another way: "Those who benefit from the Matthew effects strive to protect not only their golden eggs, but also the goose that laid them" (Rigney, 2010, p. 105).

In this context, coincidence and luck ought to be given more attention and more serious and explicit consideration within 
elite sport development programs. However, efforts to introduce reform to the elite sport development programs seem to be based on opposite assumptions - they consistently draw on the conjecture of a high degree of predictability and feasibility. The fact that coincidence and luck play an important role, and that sports organizations demand more predictability, is not a contradiction. However, it becomes a problem when all efforts at introducing reform are designed in a way that they not only demand, but also rely on a high level of predictability and feasibility - including the individual athlete level (individualistic approach) - and all reform concepts are based on the assumed predictability and "producibility". With the possible existence of positive self-reinforcement (Matthew mechanism) the effectiveness of the progressing introduction of market economy incentives in sport development programs has to be evaluated since we no longer should automatically/implicitly assess these incentives as having a positive impact on the production of sporting success.

Finally, the sport organizations envisage irreconcilable internal and external social expectations, in that they are, on the one hand, expected to "deliver" collective success while, on the other hand, adhering to the common ideology of talent development, implying the early identification of future high-performers and their long-term continuous nurture through talent identification and talent development programs. The organizations apparently "resolve" these contradictory expectations by a functional decoupling of "talk" and "action" (Brunsson, 2002). Their action aligns with the logic of a collectivist approach, implying repeated selection and de-selection processes, and replacement of athletes. At the same time, the normative concept and claim of talent development emphasizing the individualistic approach is demonstratively communicated to the outside world. This is supported by the rationality myth of elite sport development programs (cf. Emrich \& Güllich, 2005), and thus serves to engender trust and generate external resource supply (Güllich \& Emrich, 2012).

\section{Limitations of the study and future directions}

This study did not aim to examine the contribution of an athlete's characteristics or system-related causes as to the concentration of success nor to prove the existence of a Matthew effect (cf. Bask \& Bask, 2015) or scrutinize an agent-based differentiation between Pygmalion and Galatea effects ${ }^{10}$ (as suggested by Hancock, Adler, \& Côté, 2013). Our interest focused on the effects of a potential Matthew mechanism, rather than the explanation of its emergence. We acknowledge that each, the relation between athlete support programs and success, individual and social causes of concentrated success as well as social mechanisms of a potential Matthew effect in the athlete

10 "Principally, the Pygmalion effect refers to the perception that the greater the expectation placed on an individual, the greater the result that individual will attain" (Hancock et al., 2013, p. 632). In contrast, the Galatea effect refers to a person's own subsequent expectation of her or himself (Hancock et al., 2013). development system, warrant deeper research. Athlete support services may be followed by increased success and success may be followed by enhanced athlete promotion. Causal directions - if any exist - cannot be determined based on the available data.

The high concentration of medaling success not only questions the way success is traditionally operationalized in empirical studies but also prompts further examination of the causes for the concentration of success. For example, the chronology of multiple and serial medaling success, these athletes' developmental career pathways as well as their survival functions compared to singular medalists may be scrutinized. Furthermore, the present sample was highly selective and it would be interesting to extend research on the scope of the findings, for example considering not only medals but also e.g., $4^{\text {th }}-10^{\text {th }}$ places or winners of Alpine globes of the International Ski Federation, expand analyses to regional level squads who are lower in age and performance level, and to other sports and countries. Finally, it has to be said that the study takes the form of an initial case study. With the results of this study there seem to exist first indications that the multiple medalist in alpine ski racing should not be seen as an exceptional individual outlier, but rather as a systematic phenomenon. However, further studies are needed to verify this assumption for alpine ski racing and other sports.

\section{Funding}

The authors have no funding or support to report.

\section{Competing Interests}

The authors have declared that no competing interests exist.

\section{Data Availability Statement}

All relevant data are within the paper.

\section{References}

Akerlof, G. (1976). The economics of caste and of the rat race and other woeful tales. The Quarterly Journal of Economics, 90(4), 599-617.

Austrian Ski Federation (Ed.) (n.y.a). Qualifikationsrichtlinien - Kadermodus ÖSV Ski Alpin Herren 2017/2018. Retrieved from http://www.tirolerskiverband.at/fileadmin/data/Leistungssport/Alpin/Qualifikationsrichtlinien_OESV_Herren_2017-18.pdf

Austrian Ski Federation (Ed.) (n.y.b). Qualifikationsrichtlinien - Kadermodus ÖSV Ski Alpin Damen 2017/18. Retrieved from http://www.tirolerskiverband.at/fileadmin/data/ Leistungssport/Alpin/Qualifikationsrichtlinien_O__SV_ 
Damen_2017-18.pdf

Barth, M. (2015). Zur "Produktion" sportlichen Erfolgs in Österreich. Doctoral thesis, University of Innsbruck, Innsbruck.

Barth, M., Emrich, E., \& Daumann, F. (2017). Evaluation of sporting success in Austria - an institutional economics analysis. Journal of Contemporary Management, 7(2), 16-30. Retrieved from www.bapress.ca/jcm/jcm-article/19290136-2017-02-16-15.pdf

Bask, M. \& Bask, M. (2015). Cumulative (dis)advantage and the Matthew Effect in life-course analysis. PLOS ONE, 10(11), e0142447. doi: 10.1371/journal.pone.0142447

Bewick, V., Cheek, L., \& Ball, J. (2004). Statistics review 12: survival analysis. Critical Care, 8(5), 389-394. doi: 10.1186/cc2955

Bonetti, D. L. \& Hopkins, W. G. (2010). Variation in performance times of elite flat-water canoeists from race to race. International Journal of Sports Physiology and Performance, 5(2), 210-217. doi: 10.1123/ijspp.5.2.210

Bortz, J. \& Schuster, C. (2010). Statistik für Human- und Sozialwissenschaftler (7., vollst. überarb. u. erw. Aufl.). Heidelberg/ Berlin: Springer.

Brunsson, N. (2002). The organization of hypocrisy: talk, decisions, and actions in organizations ( $2^{\text {nd }}$ ed.). Oslo: Copenhagen Business School Press.

Bullock, N., Hopkins, W. G., Martin, D. T., \& Marino, F. E. (2009) Characteristics of performance in skeleton World Cup races. Journal of Sports Sciences, 27(4), 367-372. doi: $10.1080 / 02640410802613425$

Bundesministeriums des Innern, Deutscher Olympischer Sportbund, \& Sportministerkonferenz (Eds.) (n.y.). Neustrukturierung des Leistungssports und der Spitzensportförderung: Gemeinsames Konzept des Bundesministeriums des Innern und des Deutschen Olympischen Sportbundes unter Mitwirkung der Sportministerkonferenz. Retrieved from https://www.dosb.de/fileadmin/fm-dosb/Konzept_Neustrukturierung_des_Leistungssport_und_der_Spitzensportfoerderung.pdf

Carlson, R. (1988). The socialization of elite tennis players in Sweden: an analysis of the players' backgrounds and development. Sociology of Sport Journal, 5(3), 241-256. doi: 10.1123/ssj.5.3.241

Collins, D., MacNamara, Á., \& McCarthy, N. (2016). Super champions, champions, and almosts: important differences and commonalities on the rocky road. Frontiers in Psychology, 6, published online 11 January 2016. doi: 10.3389/fpsyg.2015.02009

De Bosscher, V., Bingham, J., Shibli, S., van Bottenburg, M., \& de Knop, P. (2008). The global sporting arms race: an international comparative study on sports policy factors leading to international sporting success (SPLISS). Oxford: Meyer \& Meyer Sport.

Emrich, E. (1996). Zur Soziologie der Olympiastützpunkte: Eine Untersuchung zur Entstehung, Struktur und Leistungsfähigkeit einer Spitzensportfördereinrichtung. Niedernhausen: Schors.

Emrich, E. (2010). Nachhaltigkeit in der Sportförderung von Kindern und Jugendlichen. In F. Bockrath (Ed.), Kindheit und
Jugend im Fokus der Sportwissenschaft: 24. Darmstädter-Forum (pp. 63-87). Technische Universität Darmstadt/Institut für Sportwissenschaft.

Emrich, E., Fröhlich, M., Klein, M., \& Pitsch, W. (2009). Evaluation of the elite schools of sport: empirical findings from an individual and collective point of view. International Review for the Sociology of Sport, 44(2-3), 151-171. doi: $10.1177 / 1012690209104797$

Emrich, E., Gassmann, F., Haut, J., Pierdzioch, C., \& Prohl, R. (2015). Medaillen für die nationale Repräsentanz? Zur Bedeutung von Medaillenerfolgen bei Olympischen Spielen: Who believes in Olympic medal counts? Sport und Gesellschaft - Sport and Society, 12(1), 39-67. doi: 10.1515/sug2015-0103

Emrich, E. \& Güllich, A. (2005). Zur "Produktion" sportlichen Erfolges: Organisationsstrukturen, Förderbedingungen und Planungsannahmen in kritischer Analyse. Köln: Sport und Buch Strauß.

Emrich, E. \& Güllich, A. (2016). Produktion sportlichen Erfolgs. In C. Deutscher, G. Hovemann, T. Pawlowski, \& L. Thieme (Eds.), Handbuch Sportökonomik (pp. 139-162). Schorndorf: Hofmann.

Emrich, E. \& Pierdzioch, C. (2012). Das Vademecum der Evalualogie: Neue Arten im Biotop der Wissenschaft. Saarbrücken: Universaar.

Emrich, E., Pierdzioch, C., \& Rullang, C. (2013). Zwischen Regelgebundenheit und diskretionären Spielräumen: Die Finanzierung des bundesdeutschen Spitzensports. Sport und Gesellschaft 10(1), 3-26. doi: 10.1515/sug-2013-0102

Flatau, J. \& Emrich, E. (2013). Asset specificity in the promotion of elite sports: Efficient institutions of governance for the "production" of long-term future sport success. International Journal of Sport Finance, 8(4), 327-340.

Gould, D., Dieffenbach, K., \& Moffett, A. (2002). Psychological characteristics and their development in Olympic champions. Journal of Applied Sport Psychology, 14(3), 172-204. doi: 10.1080/10413200290103482

Güllich, A. (2014a). Selection, de-selection and progression in German football talent promotion. European Journal of Sport Science, 14(6),530-537.doi: 10.1080/17461391.2013.858371

Güllich, A. (2014b). Many roads lead to Rome - developmental paths to Olympic gold in men's field hockey. European Journal of Sport Science, 14(8), 763-771. doi: 10.1080/17461391.2014.905983

Güllich, A. (2017). Developmental sport activities of international medalists and non-medalists - a matched-pairs analysis. Journal of Sports Sciences, 35(23), 2281-2288. doi: 10.1080/02640414.2016.1265662

Güllich, A. (2018). Sport-specific and non-specific practice of strong and weak responders in junior and senior elite athletics - A matched-pairs analysis. Journal of Sports Sciences, advanced online publication. doi: 10.1080/02640414.1449089

Güllich, A., Anthes, E., \& Emrich, E. (2005). Talentförderung im Sportverein. Teil 2: Interventionen zur Talentsuche und -förderung. Leistungssport, 35(6), 48-55. 
Güllich, A. \& Cobley, S. (2017). On the efficacy of talent identification and talent development programmes. In J. Baker, S. Cobley, J. Schorer, \& N. Wattie (Eds.), Routledge handbook of talent identification and development in sport (pp. 80-98). Oxon/New York: Routledge.

Güllich, A. \& Emrich, E. (2012). Individualistic and collectivistic approach in athlete support programmes in the German high-performance sport system. European Journal for Sport and Society, 9(4), 243-268. doi: 10.1080/16138171.2012.11687900

Güllich, A. \& Emrich, E. (2013). Investment patterns in the careers of elite athletes in East and West Germany. European Journal for Sport and Society, 10(3), 191-214. doi: 10.1080/16138171.2013.11687919

Güllich, A. \& Emrich, E. (2014). Considering long-term sustainability in the development of world class success. European Journal of Sport Science, 14(sup1), S383-S397. doi: 10.1080/17461391.2012.706320

Güllich, A., Papathanassiou, V., Pitsch, W., \& Emrich, E. (2001). Kaderkarrieren im Nachwuchs- und Spitzensport - Altersstruktur und Kontinuität. Leistungssport, 31(4), 63-71.

Hancock, D. J., Adler, A. L., \& Côté, J. (2013). A proposed theoretical model to explain relative age effects in sport. European Journal of Sport Science, 13(6), 630-637. doi: 10.1080/17461391.2013.775352

Hardy, L., Barlow, M., Evans, L., Rees, T., Woodman, T., \& Warr, C. (2017). Great British medalists: psychosocial biographies of super-elite and elite athletes from Olympic sports. In V. Walsh, M. Wilson, \& B. Parking (Eds.), Sport and the brain: the science of preparing, enduring and winning, part $A$ (pp. 1-119). Cambridge [i.a.]: Elsevier.

Haut, J., Prohl, R., \& Emrich, E. (2016) Nothing but medals? Attitudes towards the importance of Olympic success. International Review for the Sociology of Sport, 51(3), 332-348. doi: $0.1177 / 1012690214526400$

Held, U. (2010). Grafische Darstellung und Vergleich von Überlebenszeitverläufen. Swiss Medical Forum, 10(33), 548-550.

Hopkins, W. G. (2005). Competitive performance of elite trackand-field athletes: Variability and smallest worthwhile enhancements. Sportscience, 9, 17-20. Retrieved from http:// www.sportsci.org/jour/05/wghtrack.pdf

Hornig, M., Aust, F., \& Güllich, A. (2016). Practice and play in the development of German top-level professional football players. European Journal of Sport Science, 16(1), 96-105. doi: 10.1080/17461391.2014.982204

Humphreys, B. R., Johnson, B. K., Mason, D. S., \& Whitehead, J. C. (2016). Estimating the Value of Medal Success in the Olympic Games. Journal of Sports Economics, advanced online publication. doi: 10.1177/1527002515626221

Johnson, M. B., Tenenbaum, G., \& Edmonds, W. A. (2006). Adaptations to physically and emotionally demanding conditions: the role of deliberate practice. High Ability Studies, 17(1), 117-136. doi: 10.1080/13598130600947184

Malcata, R. M. \& Hopkins, W. G. (2014). Variability of competitive performance of elite athletes: A systematic review. Sports
Medicine, 44(12), 1763-1774. doi: 10.1007/s40279-0140239-x

McGuigan, M. R. \& Kane, M. K. (2004). Reliability of performance of elite Olympic weightlifters. Journal of Strength and Conditioning Research, 18(3), 650-653. doi: 10.1519/12312.1

Merton, R. K. (1968). The Matthew effect in science: the reward and communication systems of science are considered. Science, 159(3810), 56-63.

Meyer, J. W. \& Rowan, B. (1977). Institutionalized organizations: formal structure as myth and ceremony. American Journal of Sociology, 83(2), 340-363.

Moesch, K., Elbe, A.-M., Hauge, M.-L. T., \& Wikman, J. M. (2011). Late specialization: the key to success in centimiters, grams, or seconds (cgs) sports. Scandinavian Journal of Medicine and Science in Sports, 21(6), e282-e290. doi: 10.1111/j.16000838.2010.01280.x

Moesch, K., Hauge, M.-L. T., Wikman, J. M., \& Elbe, A.-M. (2013). Making it to the top in team sports: Start later, intensify, and be determined! Talent Development \& Excellence, 5(2), 85-100.

Nibali, M., Hopkins, W. G., \& Drinkwater, E. (2011). Variability and predictability of elite competitive slalom canoe-kayak performance. European Journal of Sport Science, 11(2), 125-130. doi: 10.1080/17461391.2010.487121

Oakley, B. \& Green, M. (2001). The production of Olympic champions: international perspectives on elite sport development systems. European Journal for Sport Management, 8(special issue), 83-105.

Paton, C. D. \& Hopkins, W. G. (2005). Competitive performance of elite Olympic-distance triathletes: Reliability and smallest worthwhile enhancement. Sportscience, 9, 1-5. Retrieved from http://www.sportsci.org/jour/05/wghtri.pdf

Paton, C. D. \& Hopkins, W. G. (2006). Variation in performance of elite cyclists from race to race. European Journal of Sport Science, 6(1), 25-31. doi: 10.1080/17461390500422796

Pierdzioch, C., Emrich, E., \& Klein, M. (2014). Die optimierende Diktatur - Politische Stabilisierung durch staatliche verordnetes Doping am Beispiel der DDR. Vierteljahresschrift für Sozial- und Wirtschaftsgeschichte, 101(1), 23-48.

Rigney, D. (2010). The Matthew effect. How advantage begets further advantage. New York/Chichester, West Sussex: Columbia University Press.

Smith, T. B. \& Hopkins, W. G. (2011). Variability and predictability of finals times of elite rowers. Medicine \& Science in Sports \& Exercise, 43(11), 2155-2160. doi: 10.1249/ MSS.0b013e31821d3f8e

Spencer, M., Losnegard, T., Hallén, J., \& Hopkins, W. G. (2014). Variability and Predictability of Performance Times of Elite Cross-Country Skiers. International Journal of Sports Physiology and Performance, 9(1), 5-11. doi: 10.1123/ ijspp.2012-0382

Van Rossum, J. H. A. (2000). Deliberate practice and Dutch field hockey: an addendum to Starkes. International Journal of Sport Psychology, 31(4), 452-460. 
Werron, T. (2012). Worum konkurrieren Nationalstaaten? Zu Begriff und Geschichte der Konkurrenz um „weiche“ globale Güter. What Do Nation-States Compete for? A HistoricalSociological Perspective on Competition for "Soft" Global Goods. Zeitschrift für Soziologie, 41(5), 338-355. doi: 10.1515/zfsoz-2012-0502

Wissenschaftliche Dienste des Deutschen Bundestages (Ed.) (2012). Spitzensportförderung des Bundes: Das System der Zielvereinbarungen vor dem Hintergrund aktueller Sportereignisse. Retrieved from https://www.bundestag.de/blo b/411734/8d5450b4d95d2f355617da578fd19263/wd-10096-12-pdf-data.pdf

Zwiener, I., Blettner, M., \& Hommel, G. (2011). Überlebenszeitanalyse. Teil 15 der Serie zur Bewertung wissenschaftlicher Publikationen. Deutsches Ärzteblatt, 108(10), 163-169. doi: 10.3238/arztebl.2011.0163 